\title{
Bowon Power: An Integrated of Community Development Mechanism in Nakhon Pathom Province
}

\author{
Pramaha Prakasit Thitipasitthikorn ${ }^{1}$, Phrakhrudhammakut (Suttipot Sappaso) ${ }^{2}$, Phrapalad Prapoj \\ Yusamran $^{3}$, Warinee Sopajorn ${ }^{4}$, Rungroje Songsraboon ${ }^{5}$ \\ ${ }^{1,3}$ Mahachulalongkornrajavidyalaya University \\ ${ }^{2,4}$ Mahamakut Buddhist University \\ ${ }^{5}$ Siam University \\ Email:1Prakasit.mcu@gmail.com, 2dhammakut.sa@mbu.ac.th, ${ }^{3}$ prapoj1243@gmail.com, ${ }^{4}$ warinee.sop@mbu.ac.th, \\ ${ }^{5}$ rrs101@ hotmail.com
}

\begin{abstract}
This research has the objective to study citizenship awareness in community development and urbanization of Nakhon Pathom province. Using the integrated research methodology, namely quantitative research The quantitative data were collected from 375 samples. The data were analyzed by using percentage, mean, standard deviation. And qualitative research 24 in-depth interviews with key informants/person and 12 specific group conversations/person, analyzing data in context and describing.

The research found that The community development and urbanization of communities in Nakhon Pathom Province. From the study of the context of community development and urbanization of urban communities in the study area, it can be seen that the mechanism of urbanization is "Power Bowon" with "Community Funds" that are fundamental factors that drive communities to develop. Cooperation from civil society Having visionary leaders wants to see the development of the area in various dimensions. The reliance between community organizations and people, namely the state temple and the communities in which each side performs their duties appropriately. And co-ordinate working together which affects the quality of life of the people in the community who are the direct recipients of urban development Although some community development activities are not initiated by people in the community, but with various sectors being able to coordinate and collaborate And join together to drive development that will benefit the people in the community People are affected by the development activities. Therefore, creating a shared awareness as a force to drive community development activities into urbanization and is an expression of good citizenship by democracy.

These instructions give you guidelines for preparing papers for the International conference ICCSE). Use this document as a template if you are using Microsoft Office Word 6.0 or later. Otherwise, use this document as an instruction set. The electronic file of your paper will be formatted further at International Journal of Computer Theory and Engineering. Define all symbols used in the abstract. Do not cite references in the abstract. Do not delete the blank line immediately above the abstract; it sets the footnote at the bottom of this column
\end{abstract}

Keywords

Network Conscious, Good Citizenship, Buddhist Community

Article Received: 10 August 2020, Revised: 25 October 2020, Accepted: 18 November 2020

\section{Introduction}

In globalization is an era of communication technology without borders. As a reason for the prosperity of modern technology, spread all over the world without borders, blocking in the relationship between the economy, politics and cultural exchange, social change, communication development, transportation, and information technology. Demonstrate the growth of economic, political, technological, and cultural relations linking individuals, communities, business entities, and government. This brings up a number of social problems that are threatening the country today, such as health and environmental issues, problems with lawlessness or rights violations, and social conflicts [1]. In particular, there are more and more people who practice the good immorality of religion in any field or any institution, as it always appears in the news on newspapers and other media. The source of the problem is the lack of good citizenship consciousness. Therefore, it is highly deserved to be extended and developed in terms of knowledge, skills, and attitudes to create a good relationship with the community and society. Learn and understand the culture, traditions, wisdom, laws, and the role of good citizenship. In addition, people have the right to freedom of expression in protection under the provisions of the Constitution of the Kingdom of Thailand, even though they are internationally accepted. In the rise of materialism and consumerism and began to adopt inappropriate foreign cultures, until making the culture of good values, which is a religious principle and uniqueness in Thai, including the way of life of Thai people, has changed as different people live, lack of generosity for each other. By considering only their own interests causing a lack of awareness of social responsibility. Nipawan [2] said that the development of the country continues to progress is need for intelligence and abilities of the people of the nation, especially children and youth who are the age of learning, creativity, and is a vital force in driving the direction of the country in a correct and appropriate way. As for the Great Decree Thitipasitikorn et al.[3] said that promoting morals and ethics for good citizenship Cannot lift the burden on an educational institution or school alone. The stakeholders should cooperate with the shin and earnestly. 1) Family institute Parents or guardians, which serves to instill moral and ethical transfer to family members as the first priority. 2) Elders and family members, children learn ethical attitudes 
from adults and imitation rather than hear the commands of adults directly. 3) Friends play an important role in shaping the moral and ethical values that children know and apply to the behavior of their friends. 4) Educational establishment or school environment arrangement, educational services, being a good example of a teacher, teaching, and organizing activities promoting morals and ethics, being a consultant like a good friend. 5) Monks are a moral leader in society. 6) The media is very important to guiding society, it can change attitude values as well as the behavior of the people in society, therefore, the cooperation promotes the development of youth to have a good consciousness. Therefore, requires cooperation in the form of "bowon" that is all sectors in society, including family institutions, educational institutions, religious institutions, community organizations together as a social network to develop human resources of the nation to realize the common sense of goodness.

In addition, in driving community development to become a strong city, it is essential that cooperation is participation from all sectors, especially people in the area. Creating good awareness of community development and building network participation for the development of good citizenship consciousness. Therefore, creating a fair balance in the interests of all sectors, that focus on the integration of the citizenship network and sustainable community, through holistic development to achieve a balance of development and capital utilization, including economic, social, cultural, and intellectual capital []. Including integrating the principles of Buddhism to be in line with the potential to strengthen the youth conscious network by using various activities in temples, schools, and communities as tools, inserting knowledge, skills, and attitudes that will enable the ability to be applied in daily life. As well as being able to transfer and expand knowledge on promoting physical and mental health, activities to promote good citizenship, adhere to the legal system and the judicial process. Also strengthened the attitude of solidarity, the principles of Buddhism is applied in order to raise awareness of citizenship in the community. The principles of Buddhism have been applied as a mechanism to drive consciousness generation [4]. All sectors are focus on and consciousness of cooperation in the form of a network to create a sense of citizenship that will affect the community development that is solid, stable, and sustainable together.

Therefore, this research is the study of good citizenship awareness in community development and Buddhist urbanization in Nakhon Pathom Province, through community participation which is the foundation of democratic citizenship, which will show the consciousness in driving community development from community capital like economic capital, social capital, cultural capital, and wisdom capital. Including the integration of religious principles that are consistent with the way of life of the people in the community. The fundamental and ethical context for the development of a good citizenship consciousness in community development, from participation in community development activities conducted by various sectors such as temples, schools, local government organizations, and communities. It is also a tool to interpolate knowledge, skills, attitudes that help to create awareness to be applied in daily life. As well as being able to pass on the knowledge of Buddhism as a mechanism for driving the awareness of good citizenship, which will affect the development of the community towards urbanization, that has peace, strong harmony, and sustainability.

Research objectives

To study the process of raising awareness of good citizenship in community development and urbanization in Nakhon Pathom Province according to Buddhism principles and a study of citizenship awareness in community development and urbanization of communities in Nakhon Pathom Province.

\section{Literature review}

The research team researches related documents and research to be a guideline for the study of citizenship consciousness in community and urban development.

\section{The study of concepts about building good consciousness.}

There have been scholars who have given the meaning of consciousness in a variety of 3 groups. 1) a group of psychoanalysts or behavioral scientists define consciousness, as consciousness is a matter of connected knowledge. Theoretically and the results are shown by external forces in accordance with the principle of reality. 2) Political economic theorists or Marxist, emphasizes the importance of class feelings, meaning consciousness refers to the mental state of consciousness knowing about ideas, feelings, and actions of their own, which are serving the interests of their own or other classes. 3) Sociologists havs defined consciousness as self-consciousness or someone else with you and social or group consciousness, social consciousness, or public consciousness, to realize and take into account the common or consider other participants. Prawet Wasi et al. [5] explained that the public consciousness for all or consciousness for the community (Non Governance Organizations- NGO) is a social tool. A focus on social contribution processes by non-profit organizations such as foundations and community clubs with the aim of 1) focus on group relationships, members must share ideologies and principles 2) a public mind, including goods public interest, public responsibility, and public accountability 3) social equity 4) social justice 5) social network 6) communication 7) vision 8) learning and 9) practice.

In the process of enhancing consciousness, there are many scholarly views on the process of raising awareness. Paiboon Wattanasiritham [7] has mentioned the process of creating a consciousness that the consciousness of people or the awareness of the community, under the influence of many environmental factors classified into 3 types. 1) Consciousness arising from external factors, refers to the process of consciousness of one person that originates from the social environment starting from parents, relatives, teachers, media, mass people, people, as well as organizations, cultures, customs, traditions, beliefs, law, religion, etc. 2) Internal consciousness means contemplation of the individual in determining value and virtue decisions, which affect behavior and conduct, especially the mental practice in order to refine ourselves to be in that way. 3) The 
interaction between external and internal factors creates consciousness. It must not be hasty to conclude that either external or internal factors cause consciousness because all things are related to each other. (1) Consciousness coming from outside is a natural entry and most of them are unaware. And (2) consciousness coming from within deliberately selective, it means knowing yourself well. It is the consciousness that a person creates by himself.

\section{The study of good citizenship in accordance with Buddhism}

The duties of a good citizen according to Buddhism is the practice of being a good citizen according to the principles which consist of 1) ethics code refers to the principles of conduct that do not hurt others. The principle of behavior should behave in a peaceful society. 2) Moral principles refer to the principles of conduct that benefit others. Good principles are useful that society sees as virtue and beauty. And 3) Moral principles refer to the principles of conduct that do not hurt others. At the same time, it creates benefits for others as well by healing the body, verbal, and mind to be normal, not persecute others. In accordance with the Dharma Pitaka [8], giving the view of raising consciousness as a leader and being a giver, leadership comes when something is given to others, but when we receive it from others, we must follow, because of the idea of receiving a follower must keep watching. However, if we think that we have something good to give to him when we have it, we will immediately lead because the one who will receive it must watch and follow me, so we must raise the youth to be conscious, be the leader and giver Buddhism teaches to "look wide, think far, high desired". 1) The broad perspective is not just ourselves and our society, but see the whole world to be wise and see the relationship system of causes and factors in all things of nature that depend on each other, have compassion in life and perform various activities as words of the Buddha for the benefit of the people, to help and support the world to have a social consciousness and develop a wholesome and creative way. 2) Think far, aiming to reach the ultimate destination, living in the present, searching for wisdom, understanding the factors of the past, do not underestimate the prevention of deterioration. Create causes that lead to future prosperity on the basis of life that is in the present develops yourself to progress all the time to complete and flourish until Nirvana. And 3) desiring high, that is, pursuing dharma, worship dharma, desires to create goodness for life, society, nation to have peace and goodness.

\section{Education of the concept of participation}

Participation is a process or action that allows people to come together. Comment and planning of activities, setting the direction of self-change of the group, organization, or community, as well as sharing responsibility, solve problems, and receive mutual benefits. It allows people to make decisions together to achieve the objectives of that activity, where participation of people is at the heart of development, both self-development, and local and social development. In accordance with Parichat Walaisathien [9], two characteristics of participation were summarized. 1)
Participation in a development process that must be consistent with the way of life and culture of the community. 2) Local political participation by decentralizing the development power for people to participate in shaping their own future. As for Phra Maha Prakit Thitipasitikorn [10], it concluded that the participation process of the people covers how people or communities develop their own ability to manage and control the use of available resources or input factors in society [11]. From the beginning of the problem to the point, all steps of monitoring for the benefit of socio-economic livelihood as necessary as part of the community members. Also have the opportunity to plan, formulate management, and evaluate results, as well as make decisions in determining their own future and communities for better living [12]. Therefore, participatory development is a process that allows people to take part in the development work, take part in thinking, making decisions, and solving problems[13]. With an emphasis on the participation of the people in the use of creativity, knowledge, wisdom, and expertise of the community together with the use of appropriate technology, worthwhile, and to benefit the public community most appropriately[14][15].

Preliminary literature review, about building a good citizenship consciousness, which is the duty of everyone in Thai society to perform. This will help keep society at peace. All people lived together in peace, resulting in the nation's development and progress that must have two qualifications. 1) Basic qualifications are common qualities of being a good citizen, such as diligent, loyal, economic, responsible, rational, generous, compassionate, and seeing the importance of the common good. And 2) peculiarity is the specific quality that society requires individuals to perform, such as democratic citizenship[16], which aims to create awareness for participation or public consciousness to happen with the people because public consciousness is one of the virtues of good citizens. The value of consciousness is the spirit of a person, organization, or society. It is the power to drive development to create a society to be strong and reconciled, leading to the development of economy, society, culture, a strong foundation of social ethics. In the process of creating a good citizenship consciousness according to Buddhism, which is a self-consciousness to do anything for the sake of the public and creative thinking is charity. Focus on doing good deeds that benefit the public, creative thinking is good thinking, does not destroy people, society, culture, nation, and environment. Both actions and words come from good thoughts, the creation of the public mind in all sectors of society are very beneficial for the quality of life of the population because they can make members of society coexist, understandably, and happily do not hijack each other and have joint social responsibility. Therefore, the review of the literature is a study of the consciousness of citizenship in community development and urbanization of communities in Nakhon Pathom Province. Through the process of participation of people in 4 sides consist of 1) decision making 2) operational 3) receiving results 4) evaluation. Participation is characterized by a process by which individuals or groups of different faculties to assist and support in various matters or activities, from participating in studies of various problems, planning, problem-solving, monitoring, and evaluation, the results will 
also be used together, etc. In addition, this participation process will serve as a tool for analyzing the causal factors for creating a shared consciousness in community development and urbanization of communities in Nakhon Pathom Province. And as a guideline for further study of the process of creating a consciousness to be good citizenship in community development and urbanization.

conceptual framework

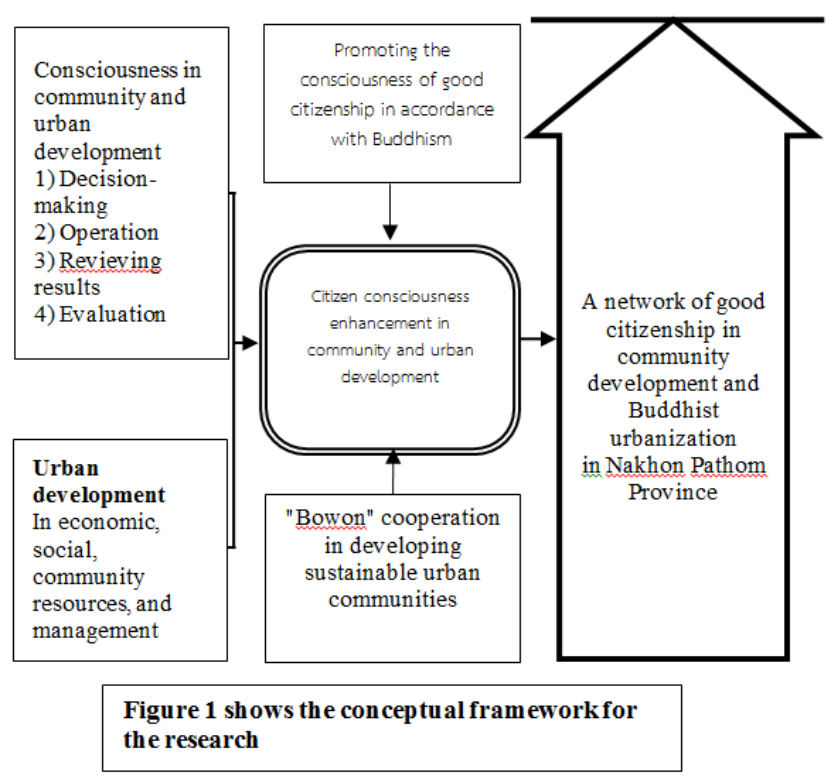

\section{Research method}

Using mixed methodology research is quantitative research. The data was collected using questionnaires and qualitative research by engaging in community activities and observing the participation behavior of the people, the data was collected by in-depth interview and focus group meeting.

\section{Research scope}

1) Content scope, a study of citizenship consciousness in community development and urbanization of communities in Nakhon Pathom Province. The research team has studied the theoretical concepts of consciousness, concepts of building a good citizenship consciousness, and the concept of participation to study the awareness of citizenship in community development and urbanization of communities in Nakhon Pathom Province.

2) Area boundary, the research team determined the study area scope, which is (1) community in Rai Khing Municipality, Nakhon Pathom 2. Areas: Ban Rai Khing Community Village No. 1 and Rai Khing - Ban Rai Community Village No. 2, Rai Khing Subdistrict, Nakhon Pathom Province (2) Community in Bang Krathuek Municipality (Don Wai Floating Market Community) including Ban Khok Wai Community, Village No. 5 and Khlong Wattana Community, Village No. 6, Bang Krathuek Sub-district, Nakhon Pathom Province.

3) Scopes of population, sample group, and important informants Population and sample in quantitative research, the research team determined the population used in this research was people living in Rai Khing municipality, Rai
Khing community areas include Ban Rai Khing Community Village No. 1 and Rai Khing - Ban Rai Community Village No. 2, totaling 3,596 people. And people living in the municipality of Bang Krathuek (Don Wai Floating Market Community) includes Ban Khok Wai Village, Village No. 5 and Khlong Wattana Community, Village No. 6, totaling 2,303 people. So the total population is 5,899 people. The sample size was determined from the comparison of Taro Yamane ready-made table, at a 95 percent confidence level, the discrepancy of $0.5,375$ samples were obtained.

Key informant in qualitative research, the researchers assigned the key informant by in-depth Interview, to confirm the data and collect insights from the quantitative study results. Using a purposive sampling from community leaders, local leaders, monks, representatives of schools, government agency representatives, and representatives of the people in the study area, totaling 24 persons.

\section{Quantitative data analysis and statistics used in data analysis}

In quantitative data analysis, the research team has already collected data from questionnaires. Therefore, the data from the questionnaire was used to analyze the data by using the statistical software for social, data analysis, and statistics used. Descriptive statistic values consist of percentages (Percentage), mean, standard deviation (SD), inferential analysis, one-way analysis of variance or One Way ANOVA), T-test, F-test.

Qualitative data analysis section, the researchers analyzed and synthesized the data by using the content analysis method. The researchers recognized the key points of this research that is the information obtained from the collection is comprehensive for the purpose of research and able to answer research problems clearly, completely, and in line with the research concept. In which the research team has chosen the triangular technique that is theory triangulation, different from method triangulation and data sources triangulation. The research team has categorized and examined the data, operate systematically by categorizing information according to the specified content, after obtaining complete information.

\section{Protection of the rights of informants}

Protecting the right of ethical informants in research, the researcher has established the protection of the group of informants, by asking for cooperation in collecting information and interviewing, and the informant is happy to provide information. In which you have the right to respond to an interview or to decline, and during the interview, you can cancel or not answer any questions without limitation. All information obtained from you will be kept confidential and will present the research results as an overview. In the in-depth interview presentation, the investigator will not disclose the person's name, which will enter the information provider code, instead of identifying the person, and enter the code in the presentation of information, instead of specifying the name of the person, who informs the information such as interviewing like the important information provider No.1. 


\section{Research results}

In the study of citizenship consciousness in community development and urbanization of communities in Nakhon Pathom Province, the research team has studied the theoretical concepts of consciousness, concepts of building a good citizenship consciousness, concepts of moral and ethical development, and the concept of participation, to study the consciousness of citizenship in community development and urbanization of communities in Nakhon Pathom Province. Creating a tool for the education of citizenship consciousness in community development and urbanization of communities in Nakhon Pathom Province, by using the concept of participation in decision making participation in action, receiving results, and the participatory evaluation, the data were collected by using questionnaires, from a sample of 375 samples. The analysis of general data on personal factors found that most of the respondents were female, which is more than male and alternative sex, accounted for 64.00 percent, while age will be in the range of 41-60 years for 49.00 percent. Most education levels have a bachelor's degree, accounting for 32.00 percent. The main occupation is trading and personal business accounted for $31.00 \%$ and had monthly income at $15,001-25,000$ baht or 43.00 percent. As for the social factors of the sample, it was found that most of the respondents had a period of time to stay in the community 515 years for 49.00 percent, had roles as residents and members of the community group, accounted for $45.00 \%$, and attended a community meeting or participated in 1-5 community development volunteer activities per year or $61.00 \%$.

1. Citizenship consciousness in community development and urbanization of communities in Nakhon Pathom Province

Analysis results of information about the consciousness of citizenship in community development and urbanization of communities in Nakhon Pathom Province. Creating a tool for the education of citizenship consciousness in community development and urbanization of communities in Nakhon Pathom Province, by using the concept of participation in decision making participation in action, receiving results, and the participatory evaluation, the data were collected by using questionnaires. Results of analysis of citizenship consciousness data in community development and urbanization of community in Nakhon Pathom Province, show with mean and the standard deviation, both overall and in each aspect, can be summarized as in Table 1.
Table 1, shows the mean and standard deviation, the level of opinion on citizenship consciousness in community development and urbanization of the community in Nakhon Pathom Province with the participation of the people as a whole.

$(\mathrm{N}=375)$

\begin{tabular}{|c|c|c|c|}
\hline \multirow{2}{*}{$\begin{array}{lr}\text { Citizenship } & \\
\text { consciousness } & \text { in } \\
\text { community } & \\
\text { development } & \text { and } \\
\text { urbanization } & \text { of } \\
\text { communities } & \text { in } \\
\text { Nakhon } & \text { Pathom } \\
\text { Province } & \\
\text { by the participation of } \\
\text { people }\end{array}$} & \multicolumn{3}{|c|}{ Comment level } \\
\hline & $x$ & S.D. & $\begin{array}{l}\text { Interpret } \\
\text { results }\end{array}$ \\
\hline 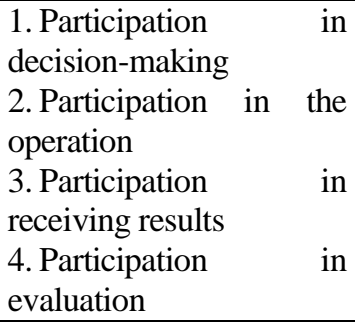 & $\begin{array}{l}3.56 \\
3.56 \\
3.58 \\
3.51\end{array}$ & $\begin{array}{l}0.97 \\
0.98 \\
1.00 \\
0.93\end{array}$ & $\begin{array}{l}\text { high } \\
\text { high }\end{array}$ \\
\hline Total & 3.56 & 0.93 & high \\
\hline
\end{tabular}

From Table 1. It shows that the respondents had opinions about citizenship consciousness in community development and urbanization of communities in Nakhon-Pathom Province. By the participation of people Overall, there was a high level of consciousness with an average of 3.56. When considering each aspect, it was found that the side with the highest score mean was participation, receiving results with the mean of 3.58 , followed by decision making and the participation of the operation had an average of 3.56. The side with the lowest mean. is the participatory evaluation had an average of 3.51. The above data shows the relationship between social factors and community to urban development, showing that most of the respondents, although not old people have lived in the community since as a population group that has come to live in the community for the last 15 years. They realize their participation in community development through their participation in community organizations and attending community meetings or participating in community development volunteer activities at a high level. The above information is consistent with interviewee 8 (5 Mar. 62) who gave information that although the community development activities in the past have not been initiated by the people in the community and their participation in the activities of the people is considered very rare in the past. But with the temple, which is a center of mind together with the administrative body, the municipality is the mainstay of the area development. Until I saw the results of a radical urban development people in the community, schools, authorities, or organizations all benefit from community development activities. Therefore, became involved in various activities such as today.

Analyzing the data of citizenship consciousness in community development and urbanization of communities 
in Nakhon-Pathom province. By the participation of people classified by side, the details are as follows.

1) Participation in decision-making. Overall, the public had a high level of consciousness with an average of 3.56. When considering each case, it was found that the item with the highest average score was that you were involved in providing various information in the community for use in decision-making, selecting activities or projects suitable for community development have an average of 3.68.

Followed by that he participated in discussions and considered various projects that may affect the development of the community. In line with interviewee number 8 (5 Mar. 62), who gave information that providing opportunities for people to take part in initiating community development activities create a sense of ownership, activities collectively, take responsibility for public relations, inform the meeting news village community motivate create awareness to create solidarity in the community. Then various cooperation will follow in line with the 24 interviewees (1 Mar. 62), who said that the public hearing process is an important part of participation because of the development is in line with the needs of the community. The fact that people within the community are grouped into a community or a community organization to express the desired goals through the representative group leaders. The participation of the people is a concept that is rooted in the concept of democracy. In conducting any community development activity, people in the community are affected and stakeholders. Therefore, there should be an opportunity to express opinions together, which is the foundation of democratic citizenship consciousness.

2) Participation in implementation. Overall, the public had a high level of consciousness with an average of 3.56. When considering each item, it was found that the item with the highest average score was that you participated in the selection of representatives to be the committees of community development activities. 3.72 corresponds to interviewee number 13 (9 June 2019) who gave information that People in the community have selected representatives to participate such as a committee on community development activities It is considered as a good conscience of democratic citizenship. Development activities or projects taking place in the community It is an expression of the participation of people in the community and in line with the interviewee number 20 (27 February 2019), who said that the organization or agency in the area and people in the community had to participate in the operation of joint activities such as choosing a leader. A community or group leader can be an agent to suggest projects or activities be held in the community. There is a community development plan. There is a concrete promotion of activities according to the plan, reflecting the conscience in participating in the activities that people in the community and community organizations are driving together. With government agencies as mentors to provide support in various fields, such as supporting speakers to educate Recommended techniques, methods, etc.

3) In the field of participation. Receiving results overall, there was a high level of consciousness with an average of 3.58. When considering each of the findings, the one with the highest average score was that you saw that the participation of people in the community would lead to stable and sustainable community development. The average value is 3.72. such information corresponds to the interviewee number 14 (9 Jun 19) who gave information that the fact that Rai Khing temple is the center of faith and spirituality together with the government agency, namely the municipality is the mainstay of the development until they see the results of the urban development progressively people in the community, schools, organizations or organizations all benefit from community development activities. Therefore, became involved in various activities such as maybe in the present because he saw that the participation of people in the community will lead to a stable and sustainable community development. The mind has volunteered to be a part of driving community development activities or public benefit activities organized by the temple or municipality and in line with the interviewee on 21 (16 Apr 2019) who said that the organization and the people in the community have been involved in receiving results from projects that have been promoted creating a career for people in the community well-being people in the community feel that they are part of the community. Activities or benefits that occur are all happening to the people and the community directly according to the needs of the people in the community leaders are contributors to driving appropriate development. People in the community make it a priority to contribute with their impact on the community.

4) Participatory evaluation. Overall, there was a high level of consciousness with an average of 3.51. When considering each case, it was found that the item with the highest average score was that you were aware acknowledge the results of activities or projects regarding community development, the average value was 3.55 , consistent with the 8th interviewee (5 Mar 19) who gave information that although the project evaluation is a duty of the municipality but organizing monthly community meetings. This is an opportunity for the community to be informed of the community development results. Is promoting the community to be aware of acknowledged the results of various projects, the public participation in following the implementation of activities or projects about the urbanization of the community and together to sum up the results doing the community to analyze the results and then report. In order to fix or improve even better in the next activities or projects.

\section{Knowledge Of Research}

A Study of citizenship consciousness in community development and urbanization of communities in NakhonPathom Province. The researchers used the concept of participation in decision making, in action participation, receiving results, and the participatory evaluation educational tools. The results of the study showed the relationship between social factors and consciousness of good citizenship in the urbanization of community development, showing that people in the community, although not old people who have lived in the community since. It is a population group that has come to live in the community in the last 15 years, but from receiving benefits from community development activities raising awareness of participation being a member of an organized group in 
the community have a sense of citizenship in a democratic system by selecting representatives to attend community meetings with government agencies. The people in the community organizations or departments in the area directly or indirectly benefit from community development activities. Including good interaction in being with the local community thus making the conscience in community development become concrete because joint consciousness is a process for people to be involved in the implementation of development, joint thinking, decision making and solving their own problems. Sharing your creativity knowledge and expertise together with appropriate speakers and support and monitor the performance of the organization and staff. In addition, receiving the result reflects the development effect. Through community leaders or corporate representatives who attended a community meeting held the public participation in the implementation of activities or projects about the urbanization of the community and together to sum up the results doing the community to analyze the results and then report. In order to modify or improve even further in the next event or project. It is a network in the community, making it convenient to thoroughly publicize information about activities in the community. Therefore, a concrete monitoring and evaluation process was established people in the community have been involved in providing information, analyze problems, propose problems, demand and select appropriate solutions to improve measures and government agencies. Play a role as a promoter supporting needs in activities such as budget support expresses coherence in society and for the process of receiving opinions from the public is an important part of participation. Because of the development is in line with the needs of the community. The fact that people within the community are grouped into a community or a community organization to express the desired goals through the representative group leaders. People in the community are affected and stakeholders. There was an opportunity to express opinions and suggest ideas together, find a common solution to drive community development activities, which is the foundation for creating good citizenship in a democracy.

From the results of the study of information in the research area on the context of community and urban development. Therefore, the research team summarizes the development model called "Palang Bowon" because it is a community-tourban development mechanism of the Rai Khing township and is a model for expanding the development results to other areas, summarized as shown in Figure 1

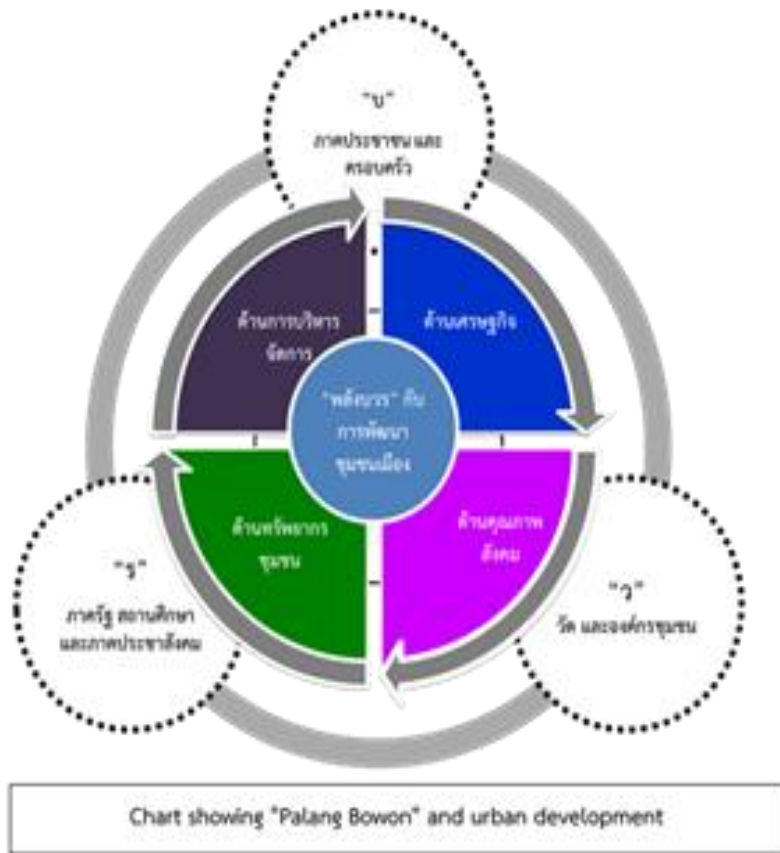

For the Bowon Power, it is a collaboration of social networks, a very important social organization and a pillar. That must be linked, sustained, supported, connected in a balanced manner as the adage known to be known and have heard each other that "The temple is good, there is evidence because the house helps. The house will be beautiful because there is a measure of bending habits. The house and the temple take turns helping each other. If they conflict, they collapse in both ways". The main "Bowon" consists of "House, Temple (Government, State)" in all 3 sectors, thus being the pillar for community development that will bring about the stability of the nation. Even at present, Thailand joins the world with rapid change. In the digital age world, there are many crises, including economic crises, global warming, environmental problems. problem of inequality, problems of moral, ethical and social, these problems require cooperation. Every sector must strive to perform their duties fully and voluntarily and introduce the science of the king into practice with concrete sufficiency economy philosophy. So that communities and rural people Urban communities develop strong, stable, prosperous and sustainable.

From the study of the community development context and the urbanization of the urban area in the study area, the urbanization mechanism is "Palang Bowon" by using the potential that is "Community capital" is a fundamental factor that will drive the community to develop further is cooperation from civil society. The leaders with altruistic vision who want to see areas developed in various fields can cultivate faith and conscience in the community. Religious places are temples that have been the center of hearts since the past. The relationship of the people in the community with the temple that is both a source for selling educational opportunities, economic sources and mentally dependent. The consistency depends on the temple and the community. This can be observed from the annual gilding festival of Rai Khing temple, Tha Phood temple, Don Wai temple, where people in the community have a good conscience. There were many volunteers to assist in various departments, government sectors, including municipalities, educational institutions, various agencies, volunteering around to help 
provide services to visitors. It expresses a good conscience in being a part of the public activities

\section{Discussion of results}

The Study of citizenship consciousness in community development and urbanization of communities in NakhonPathom province by the participation of people. Overall, there was a high level of consciousness with an average of 3.56. When considering each aspect, it was found that the side with the highest score mean was participation, affected had a mean of 3.58 , which was at the high level. Take part in decision making and the participation in the operation had an average of 3.56 at a high level. The side with the least average In terms of participation in evaluation, the mean 3.51 was at a high level In accordance with Rathaphong Boonyanuwat [4] has studied "Participation in community development of the people of Dusit district, Bangkok". The research results showed that discussion issues. From overview and aspects participation in community development of the people of Dusit district Bangkok found that overall participation in community development of people in Dusit district, Bangkok Is moderate. When considering all four aspects of decision-making participation, operations participation, receiving benefits participation, monitoring and evaluation participation is moderate. Because of most of the people are the only recipients of the information. Helpful information, including selection of community development activities or projects, information in the community to be reflected in decisionmaking on activities or projects in the community, as well as policy awareness and the implementation of the community committee budget plan. People are still not involved as much as they should and to play a role in community involvement in activities and projects is only occasionally possible [13]. With the role of community from time to time, it is not so much to follow up on the community committee's operations in accordance with plans and projects to solve problems and develop the community. Making the benefits that will be gained from activities or projects happening in the community to the people is at a moderate level only [16]. The other important issue, one of the factors that contributes to the participation of people in the development of their own community's due to occupational factors. People spend a lot of time in their careers, so they don't have as much time to get involved as they should to do. Many of them spend the rest of their career joining but others take the importance of activities and projects. In self-interest is a key issue in participation, which has been found that in the medium to high level.

\section{Suggestions}

\section{Policy Proposals}

1) Creation of a good citizenship in community and urbanization development in Buddhism. This is to develop the potential of social capital. Thailand has an urgent need to pay attention and it should be a national agenda. That must drive the creation of a good citizenship consciousness in the democratic way as a strategic development to make the development of human capital a major cost for the further development of Thai society.

2) Conceptual framework design for human capital development that emphasizes the creation of a good citizenship in democracy, to meet the holistic national development strategy, to lead to preparation for human capital development and building community power with an emphasis on personal skills participation in the community and awareness of social responsibility.

\section{Practical recommendations}

1) There should be a source of knowledge and information that will be more useful to community development activities than they are. The source of such knowledge has no time limit, you can view it at any time such as there is a reading place for the village to be a source of meeting and discussion Including various online media.

2) There should encourage people of all ages take part in expressing opinions on decisions on community development activities or joint community development plans, to express problems and opinions freely such as having a comment box and bring various suggestions. That have been shown in the community meeting to jointly acknowledge, listen and make decisions.

\section{Suggestions for the next research}

1) Good citizenship consciousness network should be promoted in community development and Buddhist urbanization in all regions of Thailand, to compare and study the democratization process of each area.

2) There should be a study of the model of networks of good citizenship in community development and urbanization on multicultural communities, to be a model for building good citizenship according to democracy and is a model of peace consciousness to live together in society.

\section{References}

[1] C. Na Chiang Mai, "Participation in balanced local community development". Bangkok: Ordinary Press Company Limited, 2002.

[2] W. Nipawan, "Applied Urban and Rural Development". Bangkok: Forpace, 2006.

[3] P.M.P. Thitipasitikorn, "Basic Concepts for Administration and Development", 2nd edition, Phra Nakhon Si Ayutthaya: MCU Press, 2020.

[4] R. Boonyanuwat, "Participation in community development of the people of Dusit District. Bangkok", Research report. Suan Sunandha Rajabhat University, Bangkok, 2009. 
[5] P. Wasi et al., "Strategies for solving the national crisis". Bangkok: Local Community Development Institute, 1999.

[6] S. Wongwiwanukit. Dictionary of Research Terms and Statistics. Bangkok: Dan Sutha Publishing, 2012.

[7] P. Wattanasiritham, "Thai realization that is desirable". Bangkok: Foundation for Rural Restoration of Thailand under the Royal Patronage of His Majesty the King, 2000.

[8] Phra Dharmitaka (P.A.Payutto), "Udomtham brings awareness of Thai society", 4th edition. Bangkok: Sahathamik, 1994.

[9] P. Walaisathien. Theories and principles of community development. Bangkok: Thammasat University, 1998.

[10] P.M.P. Thitipasitikorn, et al., "Social Network: Mechanisms for Enhancing Sustainable Quality of Life for Secondary School Students in Nakhon Pathom Province using the Principles of 5", Research Report. Office of the Health Promotion Foundation (Thai Health Promotion Foundation), 2019.

[11] P.S.P. Damnoen,P.W.V. Inthapho and Y. Chaivoramankul, "The Active Ageing in Buddhist Way Index Development of the Elderly in Retired Government Official Group", Solid State Technology, vol.63, no.2s, pp. 1333-1341, 2020.

[12] P. K. Phathong,Phrarajrattanarongkorn, S. Kenaphoom and P. S. P. Damnoen, "The Water and Environmental Resource Management in the Suay River Basin Area by the Integration of Local Knowledge to Support Sustainable Agriculture in Nong Khai Province, Thailand", Solid State Technology, vol.63, no.2s, 1909-1915, 2020.

[13] S. Kahintapongs, "Renewable Energy Policy Development in Thailand", International Journal of Multidisciplinary in Management and Tourism, vol.4. no.2, pp.148-155, 2020.

[14] C.C.Tan, P.S. P. Damnoen, Y. Toprayoon, "An Exploratory Study of the Spirituality -
Oriented Experiences of Tourists", International Journal of Advanced Science and Technology, vol. 29, no. 7, pp. 24782484, 2020.

[15] P. Kyophilavong et al., "Environmental Kuznets Curve (EKC) Hypothesis in Lao PDR: The Role of Globalization and Financial Development", International Journal of Multidisciplinary in Management and Tourism, vol.4. no.1, pp.11-27, 2020.

[16] T. Zhyber, "Conception of Local Budgeting Performance Indicators Storage', International Journal of Multidisciplinary in Management and Tourism, vol.4. no.1, pp.1-10, 2020. 